\title{
Making stem cells count for global health
}

\author{
Dominique S McMahon* \& Halla Thorsteinsdóttir
}

\begin{abstract}
Developing countries such as China, India and Brazil are making large investments in the stem cell field. Here we argue that hands-on involvement in the field by these countries is essential if the products developed are going to be locally relevant, affordable and appropriate. However, stem cells are a high-risk investment and any global health impacts are still likely to be far off. Even if they are eventually successful, better clinical oversight and measures to ensure access are required for stem cells to have a substantial and equitable impact.
\end{abstract}

Developing countries are making significant progress in niche science and technology fields and, for a few, stem cells are a key priority area. Together, the populations of China, India and Brazil represent approximately $40 \%$ of the world's population, and all three countries are still considered 'developing' by the World Bank. These three countries have made a commitment to developing stem cell research and have had significant accomplishments in the field. China is now the fifth largest publisher on stem cells in the peer-reviewed literature, Brazil is conducting one of the largest stem cell clinical trials in the world and India is repairing the corneas of hundreds of patients using limbal stem cells. Brazil has invested approximately US $\$ 40$ million in stem cell research and cell therapy since 2005, and by some estimates, China has made investments upwards of US\$300 million, although accurate numbers are hard to obtain [1,2]. While these numbers may still be low compared with some developed countries, this represents a significant investment by these countries. For example, in Brazil, stem cell spending on $\mathrm{R} \& \mathrm{D}$ represents approximately $10 \%$ of the Ministry of Health's spending on biomedical research [3]. These countries are investing significant public dollars in stem cells under the belief that it may lead to real health returns to their local populations and cement their role as international caliber innovators in a cutting-edge field of science.

\section{China is now the 5th} largest publisher on stem cells in the peer-reviewed literature, Brazil is conducting one of the largest stem cell clinical trial in the world and India is repairing the corneas of hundreds of patients using limbal stem cells. $)$

Here, we argue that this involvement is integral if stem cells are to have a real impact on health in these countries, but success is not yet guaranteed. China, India and Brazil must be involved in this field in order for stem cell technologies to be developed that adequately address local health needs and that are appropriate, affordable and accessible. Nonetheless, as we discuss, translating stem cell research to safe and efficacious treatments in these countries is challenging, as will be ensuring equitable access to eventual treatments.

*Author for correspondence: Dominique S McMahon, Dalla Lana School of Public Health, University of Toronto, Ontario, M5T 3M7, Canada; dominique.mcmahon@ utoronto.ca

Halla Thorsteinsdóttir, Dalla Lana School of Public Health, University of Toronto
We base our discussion on studies of regenerative medicine in the developing world $[4,5]$, and case studies of regenerative medicine in China, India and Brazil, published previously $[1,6,7]$.

\section{A local stem cell need}

The developing world is undergoing a costly epidemiological transition towards conditions that stem cell research aims to treat. Once known as 'diseases of affluence', the number of deaths from chronic disease far outweighs those from infectious disease in China, India and Brazil [101]. So too does the burden of disease measured in disabilityadjusted life years [101]. Unintentional injuries represent a "major and neglected component of disease burden in developing countries" and account for $8 \%$ of all disability-adjusted life years in low middle-income countries [8]. Chronic diseases and injuries are on the rise and have a profound economic and societal impact in the developing world. Brazil, India and China are estimated to forgo US $\$ 49$ billion, US $\$ 237$ billion and US\$558 billion, respectively, over a 10-year period, from heart disease, diabetes and stroke alone [101].

Stem cell applications have been shown to be directly relevant to the health needs of developing countries. In 2006, Greenwood and colleagues described the top ten applications for regenerative medicine in the developing world. These applications included novel insulin replacement and islet cell 
regeneration for diabetes, regeneration of heart muscle for cardiovascular disease, and immune system enhancement [4]. According to another study, only three developing countries had significant stem cell capacity across different sectors in 2006: China, India and Brazil [5]. We have since conducted case studies of these three countries. Our research shows that stem cell research and investments are strongly motivated by a need for new health treatments $[1,6,7]$.

Prevention is one approach that may reduce the burden of many chronic diseases, but changing behaviors and lifestyles can be slow and have limited impact - other approaches and treatments are needed. The truth of the matter is, good solutions to most chronic diseases are lacking globally. Stem cells have huge health and economic potential in the developing world, the extent of which may depend on how well these technologies are developed for their unique contexts.

$\mathbf{6}$ The truth of the matter is, good solutions to most chronic disease are lacking globally. Stem cells have huge health and economic potential in the developing world. 9

\section{Appropriate technologies require hands-on involvement}

By engaging in stem cell research from the beginning China, India and Brazil increase the chances that stem cell therapies are developed in line with the needs of their populations and that treatments are affordable, culturally appropriate and accessible. There are several indications that this is already happening.

For example, in Brazil, cardiovascular disease now represents almost a third of all deaths [9]. Brazil's Ministry of Health has funded a large Phase III stem cell clinical trial, aimed at treating four types of ischemic heart disease
[10]. One of these heart conditions is caused by Chagas disease, a neglected tropical disease endemic to Brazil. In India, the LV Prasad Eye Institute is creating corneas from limbal stem cells of the eye. According to the center, they have treated over 700 patients, many of whom have damaged eyesight caused by accidents with chemicals and materials such as lime that are often used in Indian households $[7,102]$.

It is essential that biomedical technologies are developed and used in the context of their local environment. Bone marrow transplant protocols in China and India differ from those standard to North America in order to accommodate the needs and culture of their patients [11]. Decisions on how and when to use bone marrow transplants are influenced by a family's ability to cover catastrophic health costs, the cost of imported drugs, the consistency of drug availability and availability of cell donors, among other factors [11]. Doctors may, in some situations, also opt to perform more intense treatments earlier on to reduce the number of visits to the hospital for patients where travel time away from work is prohibitively expensive. Given these protocol differences in bone marrow transplants, we can expect stem cell treatment protocols that are developed domestically to be more appropriate for their users.

Experts we spoke with in each country suggested that while realistically not all individuals would be able to afford stem cell treatments, they would be more affordable if developed domestically, and would still be more cost effective than the long-term care currently used to treat many chronic conditions. In China, many experts we spoke with believe that the lower costs of research and production give China an advantage in developing affordable treatments. Developing technology and infrastructure domestically may also increases local ownership of intellectual property and reduce reliance on developed countries for biomedical technology.
Stem cell treatments also seem to be acceptable to the general populations of China, India and Brazil. There are no major religious oppositions to stem cell use in China and India. Even in Brazil, where the legality of embryonic stem cell research was challenged by the Catholic church in the Supreme courts, $75 \%$ of the general population is completely supportive of embryonic stem cell research, with only $2 \%$ completely opposed [103].

\section{Challenges to health benefits from stem cells reaching the developing world}

The push to develop stem cell treatments in China, India and Brazil has not been without challenges. These are countries with many health priorities vying for limited resources when compared with their developed counterparts; investments in stem cell technologies are high-risk and these countries must be prepared for long-term investments before there are any tangible health returns. Aside from building up their R\&D capacity, China, India and Brazil also face significant challenges to the translation of research to effective and safe products, as well as challenges to the uptake of these treatments, including distribution pathways and equitable access issues, among others. New stem cell interventions should undergo domestic testing and approval in order to ensure these protocols do indeed serve the interests of their patients. In China and India stem cell treatments are being sold without evidence of their safety and efficacy. Without sufficient regulation and enforcement, patients are placed at risk of exploitation and may be exposed to potential financial harm, adverse health reactions and long-term complications. A lack of clear nationally and internationally accepted protocols and regulatory pathways may delay scientists from clinical testing of stem cell treatments and the availability of unproven therapies may decrease trust in the stem cell treatments both from these countries and internationally. 
The availability of stem cells will likely depend on the commercial model they follow. If stem cells resemble a pharmaceutical product that can be easily scaled up, they can then follow a distribution path similar to other drugs. If it follows a more service-based model, such as a one-to-one transplant of cells conducted in a clinical setting, access to the technology will likely depend on the level of manipulation required. Trained personnel who are comfortable administering the therapy will be needed, and specialized equipment and infrastructure may be required, limiting access to those areas with sufficient resources and skill sets. Several stem cell treatments currently in clinical trials require substantial radiation or chemotherapy along with the stem cell transplant, limiting those stem cell treatments to those who have access and can afford those parallel treatments. Currently, stem cell research occurs predominantly in a small number of large urban centers in China, India and Brazil. In order for stem cells to have an important public health impact, significant capacity to administer stem cell treatments will be needed beyond the cities in which they were developed. Stem cell R\&D has been mostly funded publicly; it is important to begin to think sooner rather than later about how resulting therapies may be broadly accessed, if stem cells are to have an important impact on health.

Our expectations of stem cells for global health must be tempered by realistic expectations of what the stem cell field is capable of producing. While there is significant excitement in this field, the initial outcomes are more likely to contribute to economic progress than real health solutions. While some products are in clinical trials, it will likely be some time before stem cell treatments are commonplace in any setting, and in particular in developing countries, and investments in stem cells must be in parallel with investments in the health system.

\section{Our expectations of stem cells for global health must be tempered by realistic expectations of what the stem cell field is capable of producing. 9}

\section{Conclusions}

Any technology with the potential to treat one or more diseases significantly affecting China, India and Brazil has an enormous potential to contribute to global health and to shape the development of a massive market. We have shown that stem cells are particularly relevant to developing country health needs and that China, India and Brazil are active in this area. These countries have chosen not to be left behind - by engaging in stem cell research and development, they improve their chances of reaping health and economic benefits from stem cells.

We must, however, mitigate our excitement over what stem cells could do with realistic expectations and understanding of the context in which they would exist. China, India and Brazil have large discrepancies in income and infrastructure within their countries, and there are still portions of the population that are unable to afford or access essential medicines. The poorest are unlikely to be able to access future stem cell treatments, and instead efforts there would be better served improving basic healthcare infrastructure and delivery. Efforts must also be taken to ensure that products are not locked into the major cities. To increase equitable access, programs will need to be designed to ensure stem cell treatments are affordable and accessible to the widest demographic possible. Stem cell treatments should be developed in parallel with improvements to health infrastructure and doctor training in all three countries. Better understanding of the risks and benefit of stem cell treatments is paramount to elucidating their impact on global health. Clinical trials will be important for validation of stem cell treatments, and to protect patients from fraud, exploitation, experimentation and abuse. We suggest that the process of stem cell translation to the clinic needs to be clarified in India and China, and call for increased oversight of clinical stem cell use until the safety and efficacy of stem cell interventions are known.

Global health challenges can benefit from a global approach to solutions. We suggest it may be an opportune time for developed countries to engage in mutually beneficial collaborative projects with China, India and Brazil. South-to-south collaborations, such as the stem cell partnership Proyectos Biológicos y Técnicos 'PROBITEC' between Brazil and Argentina, may also be a way to create capacity in the developing world, generate knowledge and increase the global health impact of emerging treatments.

\section{Key points}

- China, India and Brazil are investing public health funds in stem cell research in the hope of addressing a growing burden of chronic disease.

- By engaging in stem cell technologies from the start, China, India and Brazil increase the chance that they will be affordable, accessible, appropriate and relevant for local health needs.

- The availability of stem cells may depend on their commercial path; if provided as a one-to-one transplant, trained doctors and infrastructure may limit their availability.

- Clear clinical regulation and oversight is required to protect patients and ensure stem cell treatments are safe and effective.

- In order to increase equitable access to stem cell treatments, attention must be paid to the cost and accessibility of treatment to the widest demographic possible. 
Financial \& competing interests disclosure Our research on regenerative medicine in China, India and Brazil was funded by a Canadian Institutes of Health Research (CIHR) Net grant and was supported by the McLaughlin-Rotman Centre for Global Health. The authors have no other relevant affiliations or financial involvement with any organization or entity with a financial interest in or financial conflict with the subject matter or materials discussed in the manuscript apart from those disclosed.

No writing assistance was utilized in the production of this manuscript.

\section{Bibliography}

Papers of special note have been highlighted as:

-. of considerable interest

1 McMahon DS, Thorsteinsdóttir $\mathrm{H}$, Singer PA, Daar AS. Cultivating regenerative medicine innovation in China. Regen. Med. 5(1), 35-44 (2010).

- Presents an analysis of regenerative medicine innovation in China, including its sucesses and challenges.

2 Sogayar MC, Campos de Carvalho AC. Stem cell research in Brazil: incentives, barriers and perspectives. In: World Stem Cell Report. Genetics Policy Institute, FL, USA, 179-184 (2010).

3 Leite M. Overcoming opposition: Brazil banks on stem cells. Science 324(5923), 26-26 (2009)

4 Greenwood H, Singer P, Downey G, Martin D, Thorsteinsdóttir H, Daar A. Regenerative medicine and the developing world. PLoS Med. 3(9), e381 (2006).
- Identifies the most relevant applications for regenerative medicine in the developing world, demonstrating the relevance of stem cells to local health needs.

5 Greenwood HL, Thorsteinsdóttir H, Perry G, Renihan J, Singer PA, Daar AS.

Regenerative medicine: new opportunities for developing countries. Int. J. Biotechnol. 8(1), 60-77 (2006).

6 McMahon DS, Singer PA, Daar AS, Thorsteinsdóttir H. Regenerative medicine in Brazil: small but innovative. Regen. Med. 5(6), 863-876 (2010).

- Presents an analysis of regenerative medicine innovation in Brazil, including its sucesses and challenges.

7 Lander B, Thorsteinsdóttir H, Singer PA, Daar AS. Harnessing stem cells for health needs in India. Cell Stem Cell 3(1), 11-15 (2008).

- Presents an analysis of regenerative medicine innovation in India, including its sucesses and challenges.

8 Jamison DT. Investing in Health. In: Disease Control Priorities in Developing Countries. Jamison DT, Breman JG, Measham AR et al. (Eds). World Bank, DC, USA, 1-42 (2006).

9 Polanczyk C, Ribeiro J. Coronary artery disease in Brazil: contemporary management and future perspectives. Heart 95(11), 870-876 (2009).

10 Tura B, Martino H, Gowdak L et al. Multicenter randomized trial of cell therapy in cardiopathies - MiHeart Study. Trials 8, 2 (2007).
11 Gajewski J, Robinson P. Do affluent societies have the only options for the best therapy? Leukemia 21(3), 387-388 (2007).

- Presents key differences in bone marrow transplant protocols between developed countries with China and India. These differences make locally developed protocols more culturally relevant and affordable.

\section{Websites}

101 WHO. Preventing chronic diseases: a vital investment (2005) www.who.int/chp/chronic_disease_report/ contents/en/index.html

- Shows the burden and impact of chronic diseases in the developing world.

102 C-TRACER. A comprehensive report on the reserach activities of C-TRACER at the LV Prasad Eye Institue, Hyderabad, India (2010) www.fchampalimaud.org/images/uploads/ C-TRACER_June_2010.pdf

103 IBOPE Inteligência. População brasileira declara apoiar o uso de células-tronco para recuperação e tratamento de pessoas com doenças graves [Portuguese only]. Opinião Pública, Notícias (2008)

www.ibope.com.br/calandraWeb/servlet/ CalandraRedirect? temp $=5 \&$ proj $=$ PortalIB $\mathrm{OPE} \& \mathrm{pub}=\mathrm{T} \& \mathrm{db}=\mathrm{caldb} \& \operatorname{comp}=\mathrm{Not} \% \mathrm{E}$ Dcias \& docid $=0$ D 5622636BD7 4F018325740200621078 